\title{
Pengembangan Potensi Kalurahan Banyurejo sebagai Desa Wisata Melalui Strategi Branding Media Sosial
}

\author{
Sakir*1, Bhakti Gusti Walinegoro², Shelsa Aurelia Gunawan Putri3 \\ 1,2,3Ilmu Pemerintahan, Fakultas Ilmu Sosial dan Ilmu Politik, Universitas Muhammadiyah Yogyakarta, \\ Indonesia \\ *e-mail: mas.sakir@fisipol.umy.ac.id ${ }^{1}$, bhakti.gusti.2016@fisipol.umy.ac.id ${ }^{2}{ }_{2}$ \\ shelsa.a.isip19@mail.umy.ac.id ${ }^{3}$
}

\begin{abstract}
Abstrak
Kegiatan pengabdian masyarakat di Desa Banyurejo dilaksanakan dengan melakukan pembuatan branding desa untuk aktivitas promosi wisata. Desa Banyurejo memiliki beragam potensi wisata dan nilainilai bersejarah yang menjadi keunikan tersendiri bagi desa tersebut. Namun, di tengah melimpahnya potensi yang dimiliki Desa Banyurejo tersebut belum dapat dikembangkan secara maksimal dikarenakan terdapat faktor penghambat salah satunya yakni belum adanya branding desa untuk aktivitas promosi wisata. Metode yang digunakan adalah dengan melakukan kegiatan pemberdayaan melalui pembuatan branding desa yang disebarkan melalui platform sosial media dengan melibatkan langsung mahasiswa Universitas Muhammadiyah Yogyakarta. Branding desa dinilai menjadi hal yang penting untuk memperkuat citra desa sebagai desa wisata sekaligus sebagai media promosi untuk menarik wisatawan. Hasil dari kegiatan pemberdayaan desa ini adalah adanya branding desa yang menarik yang terdiri dari pembuatan buku profil kalurahan, desain logo, dan video profil kalurahan.
\end{abstract}

Kata kunci: Branding Desa, Desa Wisata, Pemberdayaan Masyarakat

\begin{abstract}
Community service activities in Banyurejo Village Tempel are carried out by making village branding for tourism promotion activities. Banyurejo village has a variety of tourism potential and historical values that are unique to the village. However, Banyurejo village is still facing some problems which caused by the absence of village branding for tourism promotion activities. The method used is to conduct empowerment activities through the creation of village branding that is spread through social media platforms by directly involving students of the University of Muhammadiyah Yogyakarta. Village branding is considered to be important to strengthen the image of the village as a tourist village as well as a promotional medium to attract tourists. The result of this village empowerment activity is the existence of attractive village branding consisting of the creation of kalurahan profile books, logo designs, and kalurahan profile videos.
\end{abstract}

Keywords: Social Empowerment, Tourism Village, Village Branding

\section{PENDAHULUAN}

Di era digital saat ini, pesatnya perkembangan teknologi memunculkan berbagai terobosan inovasi baru di bidang Teknologi Informasi dan Komunikasi (TIK) dan menuntut adanya digitalisasi dalam segala sektor. Pada level pemerintahan desa, digitalisasi ini membentuk sebuah konsep desa digital dimana desa dapat terkoneksi dengan fasilitas internet untuk mempercepat dan memperluas arus penyebaran informasi sekaligus membantu meningkatkan produktivitas masyarakat desa tersebut (Suyatna, 2019). Hal ini diperkuat dalam landasan Undang-undang Nomor 6 Tahun 2014 Tentang Desa dan didukung oleh Peraturan Menteri Komunikasi dan Informatika Nomor 5 Tahun 2015 Tentang Strategi Pengembangan Desa Digital yang mengamanatkan Desa untuk membangun Sistem Informasi Desa (SID) (Eprilianto et al., 2020).

SID merupakan suatu aplikasi elektronik dengan memanfaatkan koneksi internet untuk mengelola berbagai informasi desa, seperti perencanaan, administrasi kependudukan, pelaporan aspirasi maupun keluhan, pemberian layanan publik, pengelolaan aset, serta sebagai wahana komunikasi pemerintah kepada masyarakat untuk penyebaran informasi (Nurjanah \& 
Iswanto, 2021). Keterbukaan informasi menjadi salah satu hal penting dalam adaptasi teknologi dan pemanfaatan internet. Pemerintah desa atau yang dapat disebut juga kalurahan sebagai suatu badan publik dituntut untuk dapat memberikan akses pemberian informasi publik secara luas sehingga masyarakat dapat mengakses informasi tersebut dengan mudah (Suryani, 2019).

Pemanfaatan TIK dalam tata kelola pemerintah desa hendaknya dapat dijadikan sebuah peluang untuk menggali dan mengolah potensi Desa sehingga berdampak pada peningkatan taraf hidup masyarakat Desa (Rokhman, 2019). Desa yang memiliki potensi menjadi desa wisata tentunya dapat memanfaatkan TIK melalui penggunaan media sosial sebagai sarana penciptaan branding kalurahan sekaligus melakukan promosi. Konsep desa wisata merujuk pada pengembangan objek pariwisata bersumber dari kawasan dan masyarakat pedesaan yang memiliki ciri khas unik, seperti kondisi geografis, budaya, tradisi, seni, maupun nilai-nilai hidup masyarakat desa tersebut yang dapat memberikan pengalaman kepada wisatawan saat datang berkunjung (Gautama et al., 2020). Sebuah desa yang memiliki daya tarik wisata dan beberapa kali pernah dijadikan destinasi wisata secara tidak langsung dapat berpotensi menjadi desa wisata dengan pengembangan wisata berbasis masyarakat dan kearifan lokal (Faizal Rachman \& Suprina, 2019).

Pengelolaan desa wisata yang berkelanjutan perlu diawali dengan merancang branding kalurahan yang kuat dan unik. Perancangan branding merupakan pembuatan identitas untuk memperkenalkan suatu produk baik itu barang maupun jasa. Namun, saat ini sektor pariwisata rupanya juga membutuhkan branding yang kerap disebut sebagai destination branding (Kusuma, 2019). Pembuatan branding ini bertujuan untuk menunjukkan identitas wisata khas dari wilayah tersebut dan menjadi alat promosi untuk menciptakan daya tarik bagi wisatawan (Michandani \& Arida, 2019). Sebuah branding yang tepat bagi desa wisata dapat menjadi ciri khas yang unik dan melancarkan strategi pemasaran dan diharapkan dapat menjangkau banyak wisatawan.

Strategi pemasaran branding desa wisata semakin mudah dan cepat dengan memanfaatkan media sosial (Siti Nurhayati, 2021). Media sosial dianggap sebagai sarana yang paling umum dan masif dalam strategi pemasaran online di era digitalisasi (Rohimah, 2019). Sebagai contoh salah satu penggunaan media sosial untuk promosi pariwisata ialah pemerintah Kota Bandung. Dalam melakukan promosi wisata di daerahnya pemerintah Kota Bandung melalui Dinas Pariwisata dan Kebudayaan Kota Bandung membuat konten di sosial media instagram secara informatif dan persuasif untuk menarik minat wisatawan agar berkunjung (Retnasary et al., 2019).

Kalurahan Banyurejo terletak di Kapanewon Tempel, Kabupaten Sleman, dihuni penduduk berjumlah 7.898 jiwa, yang terdiri dari 3.906 laki-laki dan 3.992 perempuan. Adapun jumlah kepala keluarga yaitu 2.879 kepala keluarga dengan rincian, 2.253 kepala keluarga lakilaki dan 626 kepala keluarga perempuan. Dari jumlah kepala keluarga yang terdapat di Banyurejo, sebanyak 1.314 kepala keluarga masuk kriteria miskin. Hal tersebut menjadi permasalahan serius karena angka tersebut menunjukkan hampir setengah dari total kepala keluarga di Banyurejo tergolong miskin. Penduduk Kalurahan Banyurejo didominasi oleh penduduk usia produktif, yaitu yang berusia 15-64 tahun. Adapun mata pencaharian penduduk Banyurejo bervariasi dengan 5 jenis pekerjaan mayoritas, yaitu petani, karyawan swasta, buruh, wiraswasta, dan pegawai negeri sipil (PNS). Dilihat dari tingkat pendidikannya, penduduk Banyurejo mayoritas telah menempuh pendidikan hingga SMA/sederajat.

Dibalik berbagai macam dinamika sosialnya, Kalurahan Banyurejo ternyata memiliki beragam potensi wisata yang sarat akan nilai-nilai bersejarah. Hal ini menjadi keunikan tersendiri bagi kalurahan tersebut yang dapat dikembangkan menjadi desa wisata. Beberapa potensi wisata yang ada di Kalurahan Banyurejo ini adalah wisata Buk Renteng, Watu Jagal, Makam Habib Ahmad, dan Embung Sri Rejeki. Selain wisata alam, Kalurahan Banyurejo juga memiliki wisata kuliner, yakni bebek bacem. Namun, di tengah melimpahnya potensi yang dimiliki Kalurahan Banyurejo tersebut belum dapat dikembangkan secara maksimal dikarenakan terdapat faktor penghambat salah satunya, yakni belum adanya branding kalurahan yang mendukung untuk aktivitas promosi wisata. Melalui program Kaline yang diselenggarakan oleh Universitas Muhammadiyah Yogyakarta, yakni kolaborasi langsung antara 
dosen dan beberapa mahasiswa lintas program studi sebanyak 1 dosen dengan 2 asisten dosen serta dibantu 5 mahasiswa ini diharapkan mampu memberikan upaya pembinaan melalui kegiatan pengabdian masyarakat di Kalurahan Banyurejo. Adapun dari pihak kalurahan yang telibat, yaitu seluruh pamong kalurahan, termasuk anggota Badan Permusyawaratan Kalurahan (BPKal), pengelola Badan Usaha Milik Kalurahan (BUMKal), serta masyarakat dengan jumlah total 20 orang.

\section{METODE}

Kegiatan pemberdayaan di Kalurahan Banyurejo ini dilakukan dengan melalui pembinaan kalurahan dalam program Kalurahan Online (Kaline). Program ini merupakan program pengabdian masyarakat yang menerjunkan langsung mahasiswa dan dosen sebagai katalisator program. Program Kaline mengangkat tema digitalisasi kalurahan dan penguatan tata kelola BUMDes yang memfokuskan pada pembangunan kalurahan. Kegiatan pemberdayaan di Kalurahan Banyurejo dilakukan dengan menghasilkan 3 luaran, yakni pembuatan branding kalurahan, buku profil kalurahan, dan video profil kalurahan yang dipromosikan melalui media sosial untuk mengoptimalkan potensi wisata yang ada di kalurahan tersebut. Hal ini dikarenakan permasalahan yang sedang dihadapi oleh kalurahan Banyurejo adalah kurangnya kegiatan promosi wisata sebab belum adanya branding yang mendukung. Harapannya dengan adanya pendampingan pembuatan branding kalurahan ini dapat memperkuat citra Kalurahan Banyurejo sebagai desa wisata, dapat menarik lebih banyak wisatawan, dan memperkuat BUMDes Banyurejo. Alur program pendampingan yang dilakukan di Kalurahan Banyurejo digambarkan dalam diagram berikut:

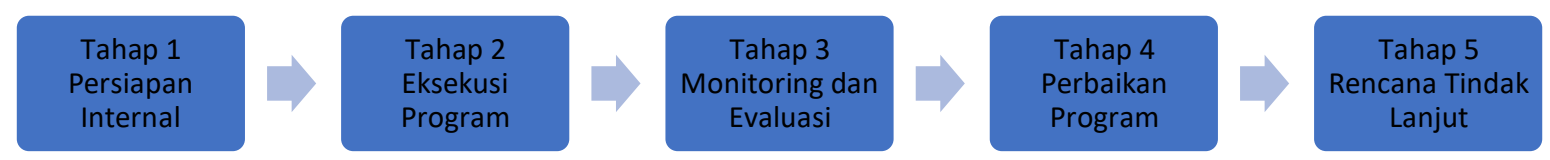

Gambar 1: Tahapan Pendampingan Branding Kalurahan Banyurejo

Pelaksanaan kegiatan pendampingan Kaline di Kalurahan Banyurejo terbagi menjadi beberapa tahapan.

\subsection{Tahap 1: Persiapan Internal}

Sebagai langkah awal dalam tahap ini berfokus pada penyiapan tim internal yang sesuai dengan kebutuhan implementasi program. Tim internal ini terdiri dari dosen pendamping dan mahasiswa dari berbagai latar belakang studi, yakni Ilmu Pemerintahan, Ekonomi Bisnis, Ilmu Komunikasi, Ilmu Hukum, dan Teknik Informatika. Kemudian, mahasiswa dan dosen tersebut akan dibagi menjadi kelompok kecil sesuai dengan kalurahan yang hendak dibina sejumlah 17 kalurahan. Setelah itu, dilakukan sesi pembekalan kepada kelompok mahasiswa dan dosen tersebut terkait proses pelaksanaan program yang disusun ke dalam buku panduan dan modul pendukung lainnya.

\subsection{Tahap 2: Eksekusi Program}

Dalam tahap ini dilakukan penerjunan mahasiswa dan dosen ke kalurahan. Kemudian tim tersebut mulai untuk observasi dan mengumpulkan data sebagai bahan dalam pembuatan buku profil kalurahan/desa, pembuatan website dan media sosial kalurahan, pembuatan Peraturan Desa (Perdes) dan AD/ART BUMDes, serta pembuatan rencana bisnis BUMDes di tiap-tiap kalurahan tersebut. Selain itu, ada pelatihan dan pendampingan kepada pengurus kalurahan terkait dengan pengelolaan SID dan BUMDes yang berkelanjutan.

\subsection{Tahap 3: Monitoring dan Evaluasi}

Pelaksanaan monitoring dan evaluasi dilakukan terhadap tim pelaksana program, keterlibatan mitra, dan kelompok penerima manfaat setiap seminggu sekali di 17 
kalurahan/desa. Tujuan dari adanya monitoring dan evaluasi ini adalah memastikan semua tahapan program dilaksanakan tetap mengacu kepada panduan pelaksanaan program. Hasil dari monev ini akan disusun menjadi sebuah laporan sebagai bahan dasar menilai tingkat keberhasilan program.

\subsection{Tahap 4: Perbaikan Program}

Tahap ini berfokus pada perbaikan program yang didasarkan pada laporan hasil monitoring dan evaluasi yang telah dilaksanakan yang selanjutnya digunakan untuk menyusun langkah-langkah perbaikan program.

\subsection{Tahap 5: Rencana Tindak Lanjut}

Di tahap terakhir ini akan dilakukan perumusan rencana tindak lanjut untuk pelaksanaan program pada masa yang akan datang. Rencana tindak lanjut tersebut disusun dalam bentuk digital yang memuat secara rinci pengembangan program.

\section{HASIL DAN PEMBAHASAN}

\subsection{Pembuatan Buku Profil Kalurahan}

Pembuatan buku profil kalurahan ini merupakan salah satu produk hasil dari pembinaan program Kaline di Kalurahan Banyurejo. Hadirnya buku profil ini harapannya dapat membantu memperkenalkan Kalurahan Banyurejo melalui karya visual yang menarik dan mudah untuk dipahami. Penyusunan konsep desain buku profil tentunya memperhatikan nilai-nilai khas yang ada di Kalurahan Banyurejo sehingga semakin memperkuat branding Kalurahan Banyurejo sebagai desa wisata.

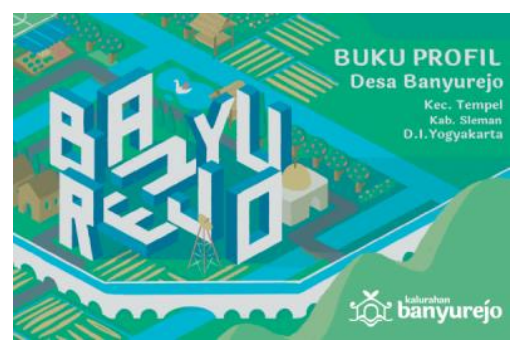

Gambar 1. Buku Profil Kalurahan Banyurejo

Buku profil Kalurahan Banyurejo memuat berbagai informasi terkait gambaran umum kondisi Kalurahan Banyurejo, seperti profil pemerintah kalurahan, sarana dan infrastruktur kalurahan, keadaan sosial budaya dan keagamaan, perekonomian desa, dan potensi desa. Dalam buku profil ini juga dicantumkan data mengenai kependudukan, sumber-sumber potensi desa, dan pendapatan kalurahan/desa. Buku profil kalurahan ini dibentuk secara digital agar dapat diunggah ke website kalurahan sehingga lebih mudah untuk diakses oleh masyarakat luas maupun para pemegang kepentingan lainnya serta dipromosikan melalui sosial media.

\subsection{Desain logo Kalurahan}

Kunci utama branding ialah adanya logo produk yang hendak dipromosikan. Sama halnya dengan Kalurahan Banyurejo yang sebelumnya belum memiliki logo branding untuk mempromosikan destinasi wisata di kalurahan tersebut, kini dengan hadirnya program Kaline dapat membantu memberdayakan Kalurahan Banyurejo untuk membuat logo khasnya sendiri sebagai ujung tombak dari promosi wisata. Desain logo Kalurahan Banyurejo ini terbilang sangat unik dan menarik sebab mengambil unsur-unsur filosofis yang menjadi ciri khas kalurahan tersebut. Logo utama Kalurahan Bayurejo berfungsi sebagai wujud identitas visual yang merepresentasikan ciri khas Kalurahan Banyurejo yang terdiri dari elemen visual logo, warna, tipografi, dan supergrafis. 


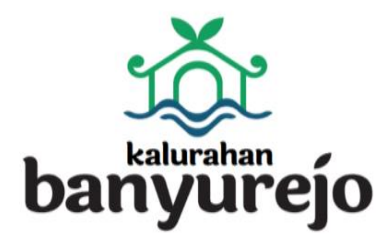

Gambar 2. Logo Kalurahan Banyurejo

Nilai brand yang terkandung dalam desain logo Kalurahan Banyurejo mengusung nilainilai kearifan lokal Kalurahan Banyurejo yang terdiri dari nilai pertumbuhan, perlindungan, kemakmuran, kebersamaan, dan kehidupan. Esensi dari branding logo ini adalah bahwa Desa Banyurejo merupakan tempat untuk tumbuh dan berlindung bagi masyarakatnya yang dijaga melalui semangat gotong royong demi tercapainya kemakmuran dengan air sebagai sumber kehidupan. Setiap unsur logonya nilai memiliki makna filosofis tersendiri terkait dengan nilai visual yang terkandung di dalamnya, antara lain unsur buk benteng sebagai perlambangan kekokohan dan warisan sejarah yang masih berdiri di Desa Banyurejo; unsur atap joglo melambangkan kentalnya kebudayaan di Desa Banyurejo yang terus dijaga dan dilestarikan; unsur daun sebagai simbol dari pertumbuhan, kemakmuran, dan kesuburan; dan unsur air sebagai pemaknaan bahwasannya air merupakan sumber kehidupan bagi masyarakat Desa Banyurejo. Logo ini juga akan diaplikasikan pada berbagai merchandise khas Kalurahan Banyurejo sebagai kenang-kenangan wisata dan sekaligus sebagai identitas promosi di sosial media.
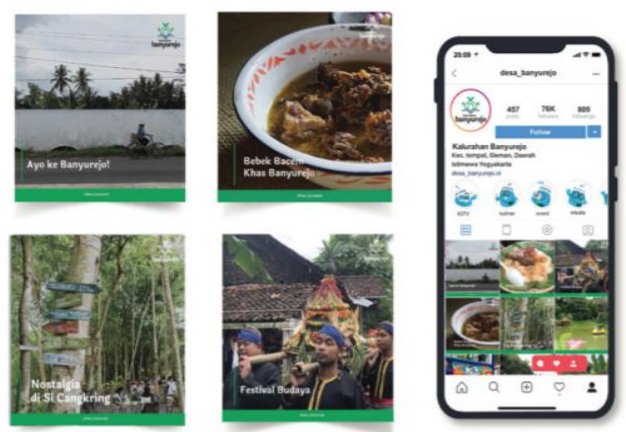

Gambar 3. Media Sosial Kalurahan Banyurejo

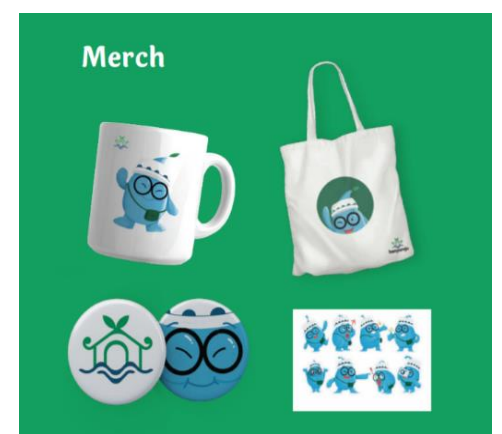

Gambar 4. Merchandise Kalurahan Banyurejo

\subsection{Dokumentasi Video Profil Kalurahan}

Selain adanya pengenalan profil kalurahan melalui buku profil kalurahan, upaya branding kalurahan juga dilakukan dengan pembuatan video profil kalurahan. Video profil kalurahan ini lebih mengedepankan pada pengenalan eksplorasi potensi wisata yang ada di 
Kalurahan Banyurejo. Video yang berdurasi 4 menit ini memandu penonton menjelajahi berbagai wisata alam dan kuliner yang ada di Kalurahan Banyurejo dengan ditemani animasi maskot kalurahan yang menarik. Maskot Kalurahan Banyurejo yang bernama Rejo ini memiliki makna representasi Kalurahan Banyurejo yang makmur, asri dan banyak potensi. Rejo juga digambarkan sebagai sosok yang gemar berpetualang dan memiliki jiwa semangat yang tinggi.

Dalam video tersebut dijelaskan secara singkat dan langsung pada poin utama setiap destinasi wisata yang dapat dikunjungi dan dijelajahi bagi para wisatawan jika berkunjung di Kalurahan Banyurejo. Segi pengambilan dan penataan video juga tidak membuat penonton jenuh, bahasa yang digunakan juga persuasif sehingga semakin menggugah rasa ingin tahu penonton untuk benar-benar datang mengunjungi Kalurahan Banyurejo.

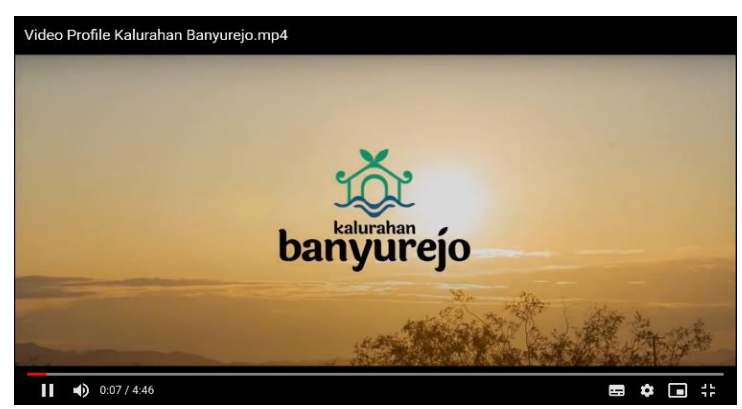

Gambar 5. Video Profile Kalurahan Banyurejo

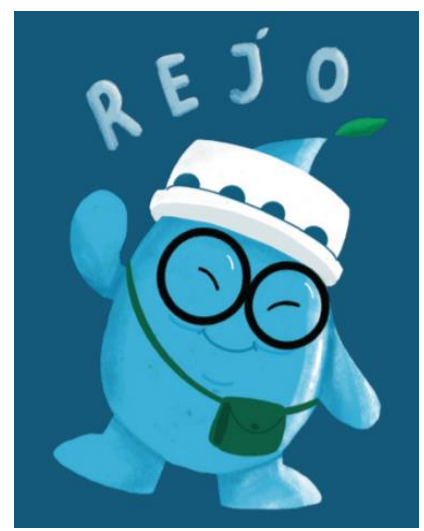

Gambar 6. Maskot Kalurahan Banyurejo

\section{KESIMPULAN}

Di era digital seperti saat ini setiap sektor kehidupan harus mampu mengadopsi perkembangan TIK yang semakin pesat. Kemajuan teknologi ini harus mampu diintegrasikan agar pekerjaan yang dilakukan semakin efektif dan efisien. Semangat adaptasi teknologi pada level pemerintah desa didukung oleh adanya Undang-undang Nomor 6 Tahun 2014 Tentang Desa dan disusul dengan Peraturan Menteri Komunikasi dan Informatika Nomor 5 Tahun 2015 Tentang Strategi Pengembangan Desa Digital yang mengamanatkan Desa untuk membangun Sistem Informasi Desa. Atas dasar hal tersebut melalui program Kaline ini mencoba untuk memberdayakan desa-desa yang memiliki potensi dengan memanfaatkan peluang TIK. Program Kaline telah berhasil memberdayakan Kalurahan Banyurejo untuk secara massif memanfaatkan TIK sebagai upaya mengatasi masalah lemahnya aktivitas promosi wisata Kalurahan Banyurejo dengan melakukan pendampingan pembuatan buku profil kalurahan, desain logo kalurahan, dan video profil kalurahan. Dengan berbagai luaran hasil pemberdayaan ini diharapkan mampu mengembangkan potensi Kalurahan Banyurejo sebagai desa wisata. Strategi branding dengan memanfaatkan sosial media yang dilakukan juga sudah cukup sebagai penguatan upaya promosi potensi wisata yang ada di Kalurahan Banyurejo. 


\section{UCAPAN TERIMA KASIH}

Ucapan terima kasih disampaikan kepada Kemendikbud Ristek dalam program Hibah Matching Fund, Kedai Reka, yang telah mendanai pelaksanaan program pengabdian ini. Selain itu, ucapan terima kasih juga disampaikan kepada mahasiswa Universitas Muhammadiyah Yogyakarta dan Desain Komunikasi Visual Institut Seni Indonesia Yogyakarta atas dukungan dalam pelaksanaan program.

\section{DAFTAR PUSTAKA}

Eprilianto, D. F., Pradana, G. W., \& Sari, Y. E. K. (2020). Digital Inovasi Sektor Publik : Efektivitas Kolaborasi Dalam Implementasi Inovasi Dega Digital. Jurnal El-Riyasah, 10(2), 127. https://doi.org/10.24014/jel.v10i2.8909

Faizal Rachman, A., \& Suprina, R. (2019). Pendampingan Desa Cipasung Menuju Desa Wisata. Jurnal Pemberdayaan Pariwisata, 1(1), 9-20. http://jurnalpariwisata.stptrisakti.ac.id/index.php/JPP/article/view/1323

Gautama, B. P., Yuliawati, A. K., Nurhayati, N. S., Fitriyani, E., \& Pratiwi, I. I. (2020). Pengembangan Desa Wisata Melalui Pendekatan Pemberdayaan Masyarakat. BERNAS: Jurnal Pengabdian Kepada Masyarakat, 1(4), 355-369. https://doi.org/10.31949/jb.v1i4.414

Kusuma, M. R. P. (2019). Perancangan Destination Branding Desa Wisata Ketenger Kabupaten Banyumas Untuk Mendukung Program Digital Destination. Desain Komunikasi Visual, Manajemen Desain Dan Periklanan (Demandia), 4(2), 116. https://doi.org/10.25124/demandia.v4i2.1897

Michandani, E. S., \& Arida, I. N. S. (2019). Perancangan Destination Branding Desa Wisata Kerta di Kecamatan Payangan Kabupaten Gianyar. Jurnal Destinasi Pariwisata, 7(1), 111. https://doi.org/10.24843/jdepar.2019.v07.i01.p17

Nurjanah, A., \& Iswanto. (2021). Digitalisasi Kelembagaan Pedukuhan melalui Sistem Informasi Desa di Dusun Nengahan Bantul DIY. Jurnal Warta LPM, 24(4).

Retnasary, M., Setiawati, S. D., Fitriawati, D., \& Anggara, R. (2019). Pengelolaan Media Sosial Sebagai Strategi Digital Marketing Pariwisata. Jurnal Kajian Pariwisata, 1(1), 76-83.

Rohimah, A. (2019). Era Digitalisasi Media Pemasaran Online dalam Gugurnya Pasar Ritel Konvensional. KANAL: Jurnal Ilmu Komunikasi, 61. https://doi.org/10.21070/kanal.v6i2.1931

Rokhman, A. (2019). Desa di Era Digital. Jurnal Ilmu Administrasi Negara ASIAN (Asosiasi Ilmuwan Administrasi Negara), 7(2), 67-75. https://doi.org/10.47828/jianaasian.v7i02.44

Siti Nurhayati, A. A. (2021). Jurnal Ekonomi Dan Bisnis. Analisis Digitalisasi Pemasaran Berbasis Sosial Media Untuk Meningkatkan Daya Saing Usaha Kecil Menengah (Ukm) Di Pekalongan, Vol. 24(2016), 66-74.

Suryani, D. A. (2019). Peran Pemerintah Desa Panggungharjo Bantul Dalam Mewujudkan Good Governance Melalui Pengembangan Sistem Informasi Desa. Journal of Public Administration and Local Governance, 3(1), 52. https://doi.org/10.31002/jpalg.v3i1.1361

Suyatna, R. (2019). Desa Digital sebuah Konsep Katalisasi Pemberdayaan Masyarakat Desa. Jurnal Lingkar Widyaiswara, 1, 22-26. www.juliwi.com 


\section{Halaman Ini Dikosongkan}

